\title{
SESELEH TATA WANGUN MANAH (STRUKTUR BATIM) LAN BASITA PARIBASA RING PUPULAN PUISI BALI ANYAR SANE MAMURDA "SANG KINASIH" PAKARDIN NI KADEK WIDIASIH
}

\author{
Kd. Sintia Ernawati ${ }^{1}$, I. A. Pt. Purnami ${ }^{1}$, I. B. Ludy Paryatna ${ }^{2}$ \\ Jurusan Pendidikan Bahasa Bali \\ Universitas Pendidikan Ganesha \\ Singaraja, Indonesia \\ e-mail: cintya erna@yahoo.co.id, dayupurnamiku@yahoo.com, \\ idabagusludy@gmail.com
}

\begin{abstract}
Kuub
Tetilik puniki matatujon nelatarang indik: (1) tata wangun manah (struktur batin), lan (2) basita paribasa sane wenten ring pupulan puisi Bali anyar sane mamurda "Sang Kinasih" pakardin Ni Kadek Widiasih. Jejering tetilik inggih punika pupulan puisi Bali anyar sane mamurda "Sang Kinasih" pakardin Ni Kadek Widiasih. Panandang tetilik inggih punika tata wangun manah (struktur batin) lan basita paribasa. Tetilikan puniki ngranjing ring tetilikan deskriptif kualitatif. Kramaning mupulang data ring tetilikan puniki nganggen kramaning dokumentasi lan nganggen piranti kartu data. Data tureksa sane kaanggen: (1) nyelehin data, (2) nyorohang data, (3) nelatarang data, lan (4) pamicutet. Pikolih tetilik pupulan puisi Bali anyar sane mamurda "Sang Kinasih" pakardin Ni Kadek Widiasih, sakadi: (1) tata wangun manah wenten patpat, sakadi: unteng, wirasa, wirama, lan piteket. (2) basita paribasa wenten 7 soroh, sakadi: sesonggan, sesenggakan, bebladbadan, sesawangan, papindan, cecangkitan, lan sasimbing.
\end{abstract}

Kruna jejaton: Tata Wangun Manah, Basita paribasa, Puisi Bali Anyar.

\section{Abstrak}

Penelitian ini bertujuan untuk menjelaskan: (1) struktur batin, dan (2) basita paribasa yang ada dalam kumpulan puisi Bali modern yang berjudul "Sang Kinasih" karya Ni Kadek Widiasih. Subjek penelitian adalah kumpulan puisi Bali modern yang berjudul "Sang Kinasih" karya Ni Kadek Widiasih. Objek penelitian adalah struktur batin dan basita paribasa. Penelitian ini masuk ke dalam penelitian deskriptif kualitatif. Metode pengumpulan data dalam penelitian ini menggunakan metode dokumentasi serta menggunakan sarana kartu data. Analisis data yang digunakan: (1) identifikasi data, (2) klasifikasi data, (3) menyajikan data, dan (4) kesimpulan. Hasil penelitian kumpulan puisi Bali modern yang berjudul "Sang Kinasih" karya Ni Kadek Widiasih, antara lain: (1) struktur batin ada empat, seperti: 
tema, rasa, irama dan amanat. (2) basita paribasa ada 7 jenis, seperti: sesonggan, sesenggakan, bebladbadan, sesawangan, papindan, cecangkitan, dan sasimbing.

Kata kunci: Struktur Batin, Basita paribasa, Puisi Bali Modern.

\begin{abstract}
This study aims to exsplain the inner structure and basita paribasa in a collection of modern Balines poetry entitled "Sang Kinasih" by Ni Kadek Widiasih. The subject of the study is a collection of modern Balinese poetry entitled "Sang Kinasih" by Ni Kadek Widiasih. The object of research is the inner structure (element in) and basita paribasa. This research goes into qualitative descriptive research. Data collection methods in this study using the method of documentation and using the means of data cards. Analysis of data used: (1) identification of data, (2) data classification, (3) presents data, (4) conclusion. The result of the study of modern Bali poetry "Sang Kinasih" by Ni Kadek Widiasih, among others: (1) the inner structure there are four, such as: sense, feeling, tone, intention. (2) basita paribasa there are 7 types, such as: sesonggan, sesenggakan, bebladbadan, sesawangan, papindan, cecangkitan, and sasimbing.
\end{abstract}

Keywords: The Inner Structure, Basita Paribasa, Modern Balines Poetry.

\section{PURWAKA}

Kasusastraan punika sinalih tunggil wangun lan pikolih ring sajeroning karya seni sane objeknyane para jana sane nganggen basa dados medianyane. Manut Gautama (2007: 2) kasusastraan inggih punika makasami kaweruhan sane madasar antuk pikenoh tur prasida kasinahang antuk tulisan sane becik tur ngulangunin. Kasusastraan manut artinnyane wenten kasusastraan Indonesia lan kasusastraan Bali. Kasusastraan Bali manut aabnyane kakepah dados kalih soroh inggih punika kasusastraan Bali purwa lan kasusastraan Bali anyar. Sane kabaos kasusastraan Bali purwa inggih punika sastra Bali sane mawit saking tetamian budaya sane dumun sane ring tengahnyane madaging guna sarat tradisi krama sane wenten ring Bali, madue wentuk sane becik, lan durung keni iusan sastra Bali anyar. Sane kabaos kasusastraan Bali anyar inggih punika kasusastraan Bali sane sampun polih iusan saking wangun-wangun sastra anyar, nganutin ring panglimbak kasusastraan Indonesia, minakadi inggih punika cerpen, novel, drama, lan puisi.
Puisi manut basanyane wenten puisi Indonesia Ian Puisi Bali. Puisi Bali wenten marupa puisi Bali purwa (tembang, gending) miwah puisi Bali anyar (puisi Bali modern). Puisi Bali anyar pateh sekadi ring basa Indonesia. Puisi Bali anyar marupa soroh sastra basa Bali, sane kaiket olih wirama tur paras puisi (tipografi). Manut Antara (2011: 20) Puisi Bali anyar inggih ipun kria sastra ri kala ngametuang manah tetueke nganggen srana basa Bali tur susunannyane kaiket nganutin uger-uger suara (rima), wirama (irama), wirasa (imaji) miwah kosa basa. Puisi Bali anyar kawangun antuk kalih unsur inggih punika struktur batin lan struktur fisik. Struktur batin (tata wangun manah) puisi sane ketah kawastanin tata wangun jeroning (unsur intrinsik) puisi, inggih ipun minakadi unteng (tema), rasa (feeling), wirama (nada) lan piteket (amanat), punika taler ring struktur fisik sane pateh sekadi unsur ekstrinsik puisi wenten paras puisi (tipografi), pilihan kruna (diksi), rerambangan (pengimajinasian), kruna sekala (kata kongkret), basa figuratif, tur wirama lan purwakanti (Utami, 2013: 89).

Kria sastra modern utamannyane puisi Bali anyar pastika nganggen basa ri 
sajeroning nyobiahangnyane mangda prasida kadadosang puisi tur prasida karesepang. Basa pinaka piranti mababosan miwah piranti anggen nyinahang rasa taler pikayunan, sane prasida kasobiahang antuk sasuratan lisan miwah pisarat. Ring kria sastra utamannyane puisi Bali anyar basa mawiguna pisan anggen ngamolihang puisi sane becik tur gaya bahasa akeh kadagingin ring puisi. Gaya bahasa punika kadadosang panglengut basa sane ketah kabaos basita paribasa. basita paribasa prasida kasengguh pinaka sarana seni mabebaosan, santukan raos sane kamedalang punika marupa raos makulit. Manut Tinggen (1988: 7) basita paribasa punika sinalih tunggil wangun kebudayaan Bali sane madaging guna sarat-guna sarat luhur, taler madue iusan ring kahuripan para jana. Basita paribasa wenten taler soroh-sorohnyane. Simpen (1980: 6) nyihnayang wenten 15 pahan basita paribasa, inggih ipun sesonggaan, sesenggakan, sesawangan, wewangsalan, sloka, bladbadan, pepindan, cecimpedan, cecangkriman, sesimbing, cecangkitan, raos gempelin, sipta, peparikan lan sasemon. Samian basita paribasa ring sajeroning puisi kaanggen panglengut basa sumangdane puisi punika prasida lengut tur ngulangunin manah.

Ring aab sekadi mangkin, puisi Bali sayan doh karasayang ring kawentenan anom-anome utamannyane ring para sisia utawi ring para mahasisia. Kawentenan punika nenten lempas saking panglimbak teknologi sekadi game. Yening cingakin, ring aabe mangkin akeh pisan gamegame sekadi game online miwah game lianan sane ngawe sang sane nganggen kecanduan, yening sampun sekadi asapunika sinah sane nganggen game punika nenten karungu ring kawentenan sekadi budaya lan sastra Bali. Pikobet punika silih sinunggil sane akeh pisan ngawinang para sisia/mahasisia lali ring kria sastra Bali utamannyane puisi Bali. Akeh para sisia/mahasisia sane nenten uning ring puisi Bali punika wenten madaging paplajahan sane pinih becik. Lianan ring nganggen basa Bali sane kaaptiang para pangwacen uning tur teleb malajahin basa Bali, ring puisi Bali taler wenten piteket-piteket sane prasida dados imba maparilaksana lan ring puisi Bali akeh pisan madaging basita paribasa sane mawiguna mangda para pangwacen uning ngeninin indik basita paribasa Bali.

Madasar saking kawentenan, kaluihan, lan piteket-piteket sane akeh wenten ring puisi Bali, parindikane punika sane ngawi panilik kadaut manahnyane jagi ngamargiang tetilikan indik puisi Bali anyar. Puisi Bali anyar sane jagi katilik inggih punika kakawian Ni Kadek Widiasih ring pupulan puisi Bali anyar sane mamurda "Sang Kinasih". Pupulan puisi Bali anyar puniki madaging 77 murda, panilik wantah nilikin 20 murda puisi Bali anyar kemanten, inggih punika Indria Tan Pawates, Gumi Blabar, Kacangkik, Dadi Caru, Muncuk Bagia, Tan Eling, Kembang Bintang, Madamar di Langit, Kena Jempulung, Macarang Beton, Semaya ring Wangaya, Sungsut, Masanding, Raja Pisuna, Ngidam Bulan, Kuluk Bengil, Buta Nyumu Kedat, Tiwas, Bajang Malong, lan Ciri-ciri. Panilik nilikin wantah 20 murda kemanten mawinan wantah 20 murda sane madaging basita paribasa.

Panilik nilikin puisi sane mamurda "Sang Kinasih" duaning ring sajeroning pupulan puisi puniki madue kaluihan inggih punika akeh madaging piteketpiteket sane mawiguna anggen sasuluh majeng ring sang sane ngwacen. Piteketpiteket punika rumasuk ring struktur batin utawi tata wangun manah puisi. Lianan ring punika taler akeh wenten basita paribasa ring pupulan puisi Bali anyar "Sang Kinasih" puniki. Dadosnyane panilik nilikin indik struktur batin lan basita paribasa sane wenten ring pupulan puisi Bali anyar sane mamurda "Sang Kinasih". Antuk punika panilik pacang nglaksanayang tetilikan sane mamurda, "Seseleh Struktur Batin (Tata Wangun Manah) lan Basita Paribasa ring Pupulan Puisi Bali Anyar sane Mamurda "Sang Kinasih" Pakardin Ni Kadek Widiasih".

Bantang pikobet tetilik: (1) Sapunapi struktur batin (tata wangun manah) sane wenten ring pupulan puisi Bali anyar sane mamurda "Sang Kinasih" pakardin Ni Kadek Widiasih?, (2) Sapunapi basita paribasa sane wenten ring pupulan puisi 
Bali anyar sane mamurda "Sang Kinasih" pakardin Ni Kadek Widiasih?

Tejujon tetilik: (1) Mangda prasida nelatarang struktur batin (tata wangun manah) sane wenten ring pupulan puisi Bali anyar sane mamurda "Sang Kinasih" pakardin Ni Kadek Widiasih, (2) Mangda prasida nelatarang kawentenan basita paribasa sane wenten ring pupulan puisi Bali anyar sane mamurda "Sang Kinasih" pakardin Ni Kadek Widiasih.

Kawigunan pamucuk sane prasida kapolihang mawiguna ngicenin pikenohpikenoh indik struktur batin (tata wangun manah) lan basita paribasa ring pupulan puisi Bali anyar Sang Kinasih. Lianan ring punika, tetilikan puniki klaksanayang antuk nglimbakang, ngwerdiang lan ngicen sasuluh utawi papineh ring para jana Bali antuk kebudayaannyane sane marupa kasusastraan Bali, utaminnyane ring puisi. Kawigunan panglimbak sane kapolihang: (1) majeng ring mahasisia, prasida kaanggen imba ring sajeroning ngaryanin utawi ngalaksanayang tetilikan sane sejenis, (2) majeng ring pangwacen, prasida kaanggen piranti pangwacenan majeng ring sang pangwacen mangda akeh madue kaweruhan indik sastra Bali, silih sinunggilnyane puisi Bali Anyar, (3) majeng ring panilik lianan, mangda prasida kaanggen pretiwimba ri kala pacang ngamargiang tatilik sane kantun mapaiketan sareng tatilikan puniki, (4) majeng ring para jana (krama), kaaptiang prasida ngwetuang lan ngicen pangresep majeng krama indik struktur batin (tata wangun manah) lan basita paribasa ring sajeroning puisi Bali anyar.

$\mathrm{Ri}$ kalan ngalaksanayang tetilik, kaperluang makudang-kudang sepat sikusuku sane mapaiketan sareng bantang pikobet sane pacang kabahbahang, tur kaanggen nuntun panilik ri kala nyelehin tetilikannyane. Sepat siku-siku inggih pinaka dasar tetimbangan utawi papineh sane pacang kaanggen ri sajeroning nglaksanayang tetilikane puniki. Wenten makudang-kudang teori sane kaanggen panuntun ri kala ngamargiang tetilikan puniki, minakadi (1) Kasusastraan Bali, (2) Puisi, (3) Struktur (Tatat Wangun) Puisi lan (4) Basita Paribasa.
Yening selehin, kruna kasusastraan mawit saking basa Sansekerta "sastra". Kruna sastra wit ipun saking kruna "sas" miwah "tra". Kruna "sas" maarti kaweruhan, lan kruna "tra" maarti piranti. Dadosnyane kasusastraan inggih punika piranti pinaka kaweruhan sane becik sane metu saking manah utawi pikayun para pangawi. Yening manut Gautama (2007: 2) kasusastraan inggih punika makasami kaweruhan sane madasar antuk pikenoh tur prasida kasinahang antuk tulisan sane becik tur ngulangunin.

Puisi inggih punika kria sastra sane kakaryanin olih pangawi ngeninin parindikan sane sampun kapanggihin lan madaging piteket-piteket sane mabuat pisan ring kahuripan (Aminuddin, 2004: 134). Ring kasusastraan Bali wenten kalih wangun sastra sane kabaos puisi inggih punika puisi Bali purwa (tembang, gending) miwah puisi Bali anyar (puisi Bali modern). Manut Antara (2011: 20) Puisi Bali anyar inggih ipun kria sastra ri kala ngametuang manah tatueke nganggen sarana basa Bali tur susunane kaiket nganutin kapatehan suara (rima), wirama (irama), wirasa (rasa) miwah kosa basa.

Ring puisi wenten kalih unsur sane ngwangun, inggih punika struktur batin (tata wangun manah) lan struktur fisik (tata wangun raga) (Waluyo, 1987: 27). Struktur batin (tata wangun manah) pateh kasengguh sekadi wangun jeroning (unsur intrinsik), nanging malianan sareng unsur intrinsik ring kria satra-kria sastra sane lianan (Utami, 2003: 89). Dane taler nguningayang kepahan struktur batin (tata wangun manah) ring puisi inggih punika: (1) unteng, (2) wirasa, (3) wirama, (4) piteket. Yening ring struktut fisik (tata wangun raga) wenten: (1) paras puisi, (2) pilihan kruna, (3) rerambangan, (4) kruna sekala, basa figuratif, lan (5) purwakanti.

Manut Simpen (2010: 5) basita paribasa teges ipun basa rinengga, punika dados rerasmen basa wiadin panglengut basa, ri kala mababaosan kalih magegonjakan anggen pasimakrama. Lianan ring punika taler Tinggen (1988: 7) maosang basita paribasa punika silih sinunggil wangun kebudayaan Bali, sane madaging guna sarat-guna sarat luhur taler madue iusan ring dasar kauripan 
parajana, sane nganggen basita paribasa ri tatkala mababaosan. Makakalih penampen saking sujana ring ajeng nenten banget matiosan. Dadosnyane prasida kacutetang, basita paribasa inggih punika sinalih tunggil wentuk kebudayaan Bali, sane madaging nilai-nilai luhur, sane marupa basa kias sane dados rerasmen basa wiadin panglengut basa ri kalaning mababaosan lan magegonjakan.

Soroh-soroh/pahan basita paribasa manut Simpen kasorohang dados limolas soroh sakadi: (1) sesonggaan, sesenggakan, (3) sesawangan, (4) wewangsalan, (5) sloka, (6) bladbadan, (7) pepindan, (8) cecimpedan, (9) cecangkriman, (10) sesimbing, cecangkitan, (12) raos gempelin, (13) sipta, (14) peparikan lan (15) sasemon.

\section{KRAMANING TETILIK}

Kramaning tetilikan inggih punika kramaning sane kanggen ri sajeroning mupulang miwah nyelehin data sane kabuatang, anggen ngamolihang panyawis pikobet sane wenten (Redana, 2004: 88). Ring tetilikan puniki nganggen kramaning tetilikan sane sampun satinut sareng pikobet miwah tetujon tetilikan. Pahan kramaning tetilikan puniki inggih punika (1) palihan tetilik, palihan tetilik inggih punika tata cara sane kaanggen sajeroning nglaksanayang tetilikan sumangdane panilik prasida polih data sane patut lan manut tekening tetilikan sane jagi kalaksanayang. Tetilikan puniki ngranjing ring soroh palihan tetilik deskripstif-kualitatif. (2) jejering lan penandang tetilik, sane dados jejering tetilik ring tetilikane puniki inggih punika pupulan puisi Bali anyar sane mamurda "Sang Kinasih" pakardin Ni Kadek Widiasih, lan sane dados panandang tetilik ring tetilikan puniki inggih punika struktur batin (tata wangun manah) lan basita paribasa. (3) kramaning mupulang data, ring tetilik puniki kramaning mupulang data sane kaanggen inggih punika kramaning dokumentasi, duaning kramaning dokumentasi punika metode sane pinih patut kaanggen ring tetilikan puniki, santukan data sane kapolihang marupa buku. (4) piranti tetilik, piranti sane anggen ngawantu ri kala mupulang data inggih punika kartu data. Ring tetilikan puniki wenten kalih data sane pacang kaselehin lan wenten kalih sane marupa tabel pacang kaanggen nyurat kawentenan struktur batin (tata wangun manah) lan basita paribasa. (5) data tureksa, data sane kapolihang katureksaan antuk makudang-kudang paletan inggih punika identifikasi data utawi nyelehin taler mupulang data manut tetujon lan kawigunan data punika, menyajikan data utawi nlatarang data sane sampun kapupulang punika dados uraian sane kawangun antuk kruna-kruna, miwah kaping nguntat makarya panyutetan (kesimpulan).

\section{PIKOLIH LAN TETEPASAN}

Pupulan puisi Bali anyar Sang Kinasih puniki kawangun antuk 78 murda puisi Bali anyar nanging paniliki ngambil wantah 20 murda kemanten, minakadi 1) Indria Tan Pawates, 2) Gumi Blabar, 3) Kacangkik, 4) Dadi Caru, 5) Muncuk Bagia, 6) Tan Eling, 7) Kembang Bintang, 8) Madamar di Langit, 9) Kena Jempulung, 10) Macarang Beton, 11) Semaya ring Wangaya, 12) Sungsut, 13) Masanding, 14) Raja Pisuna, 15) Ngidam Bulan, 16) Kuluk Bengil, 17) Buta Nyumu Kedat, 18) Tiwas, 19) Bajang Malong, lan 20) Ciri-ciri. Struktur batin (tata wangun manah) sane wenten ring pupulan puisi Bali anyar Sang Kinasih wenten patpat (4) minakadi unteng (tema), wirasa (rasa/feeling), wirama (nada) lan piteket (amanat). Pikolih lan tetepasan saking seseleh struktur batin (tata wangun manah) ring pupulan puisi Bali anyar sane mamurda "Sang Kinasih" sakadi ring sor puniki.

Puisi Bali anyar sane kapertama katilikin inggih punika mamurda puisi Indria Tan Pawates. Puisi puniki sasampunne katilikin ngamolihang 4 
struktur batin (tata wangun manah) sane jangkep. Unteng saking puisi Bali anyar sane mamurda Indria Tan Pawates puniki inggih punika watek jadma (sifat manusia). Wirasa sane karasayang ring puisi puniki krodha pisan (geram). Sasampune katilikin puisi puniki taler madue kalih wirama sane kaanggen inggih punika wirama sebet (sedih) lan wirama galak. Kaping untat piteket sane prasida kaambil ring puisi puniki kaaptiang iraga prasida ngwatesin kita/wirasa sane wenten, utamayang dumun sane patut utamayang mangda daging gumi nenten telas.

Puisi Bali anyar sane katilikin kaping kalih inggih punika puisi sane mamurda Gumi Blabar. Puisi Bali anyar puniki madue unteng inggih punika loba (tamak). Ri kala nilikin puisi puniki wenten taler wirasa sane karasayang inggih punika wirasa krodha pisan (geram). Lianan ring punika wenten taler kalih wirama sane kaanggen inggih punika wirama sebet (sedih) lan wirama galak. Sasampune katilikin, kapolihang piteket sane kaaptiang sumangdane iraga prasida ngwatesin kita/wirasa lan sampunang ngulah aluh mautsaha ngamolihang wirasa punika nyantos malaksana sane nenten patut.

Puisi Bali anyar sane kaping tiga inggih punika mamurda puisi Kacangkik sane madue unteng inggih punika nenten satya kapining samaya. Ri kala katilikin puisi Kacangkik puniki madue wirasa kuciwa, lianan ring punika wenten taler wirama sane kaanggen inggih punika wirama galak. Sane kaping untat kapolihang piteketnyane inggih punika yening iraga dados pejabat lan madue samaya kapining krama, sapatutnyane iraga prasida dados conto sane becik majeng ring krama tur samaya sane kauncarang punika prasida mabukti sumangdane krama taler satya lan percaya kapining iraga, lan sapatutnyane iraga prasida taler dados conto sane becik majeng ring krama.

Puisi Bali anyar sane katilikin kaping patpat mamurda Dadi caru. Ring puisi puniki madue unteng inggih punika pajatuh karma. Wenten taler wirasa sungsut sane prasida karasayang, lan wirama sane kaanggen ring puisi puniki inggih punika wirama sebet (sedih). Sane kaping untat piteket sane kapolihang ring puisi Dadi Caru inggih punika sampunang iraga masel-selan tekening pajalan idup sane kapolihin, yening polih pajalan idup sane nenten kaaptiang sampunang sebet, iraga patut las malaksana taler mautsaha lan malajah minab bejang pungkur polih asil sane ngawinang bagia.

Puisi Bali anyar sane kaping lima inggih punika mamurda puisi Muncuk Bagia. Ring puisi puniki wenten unteng sane kapolihang inggih punika nyujuh bagia. Lianan ring punika wenten wirasa sane karasayang inggih punika wirasa pedalem (prihatin) lan wirama galak taler sane kaanggen ring puisi puniki. Sasampune ngamolihang unteng, wirasa lan wirama, sane kaping untat kapolihang piteket sane wenten ring puisi Muncuk Bagia, piteketnyane inggih punika iraga dados jadma sampunang mautsaha nyujuh bagia sane mangkin kemanten nyantos malaksana corah, duaning rasa bagia sane kapolihang saking mlaksana corah nenten lami karasayang lan prasida taler ngawinang sesel ungkuran duaning pacang polih karma nganutin laksana punika.

Puisi Bali anyar sane katilikin kaping nemnem inggih punika mamurda puisi Tan Eling. Manut saking daging puisi Tan Eling punika sane dados untengnyane inggih punika nenten nemu kerta (tidak menemukan keadilan). Lianan ring unteng wenten wirasa sane karasayang inggih punika wirasa inguh, wusan wirasa taler wenten wirama sane kaanggen ring puisi puniki inggih punika wirama sebet (sedih). $\mathrm{Ri}$ sampune kapolihang unteng, wirasa, lan wiramanyane, sane kaping untat kapolihang piteket saking puisi Tan Elinng puniki, piteketnyane inggih punika iraga dados jadma sapatutnyane malaksana patut sumangdane nenten ungkuran wau masel-selan lan ngenehang laksana sane naenin kalaksanayang dumun ri kala sane mngkin polih asil sane nenten kaaptiang.

Puisi Bali anyar sane kaping pitu inggih punika puisi Kembang Bintang. Manut saking daging puisi Kembang Bintange punika, sane dados untengnyane inggih punika kilangan 
tresna. Ring puisi puniki wenten wirasa sane karasayang inggih punika wirasa sebet, wirasa punika sane ngawinang wenten taler wirama sane kaanggen inggih punika wirama sebet (sedih). Ri sampune ngamolihin unteng, wirasa lan wirama, sane kaping untat wenten taler piteket sane kapoliihin inggih punika ri kala iraga meled nyalanang tresna sapatutnyane cingakinn dumun sang sane katresnain punika napike sampun patut lan becik parisolahnyane, sumangdane nenten ri sampune magagelan tresnane ajebos karasayang lan gelis mapalasan yening wenten pikobet.

Puisi Bali anyar sane kaping kutus inggih punika mamurda puisi Madamar di Langit. Manut saking daging puisi Madamar di Langit punika, wenten unteng sane kapolihang inggih punika mangantosang tresna (penantian). Ring sajeroning puisi puniki taler wenten wirasa sane karasayang inggih punika wirasa sabar mangantosang. Lianan ring unteng sareng wirasa wenten wirama taler sane kaanggen ring puisi puniki inggih punika wirama bagia, lan sane kaping untat inggih punika piteket sane kapolihang. Piteket sane kapolihang ring puisi Madamar di langit inggih punika ri kala magagelan sapatutnyane iraga percaya lan satya, tur yening iraga sedek mangantosang tresna sampunang sebet lan sangsaya, sabar lan percaya patut kalaksanayang minab samian punika ungkuran pacang maasil yening sang sane katresnain sampun rauh.

Puisi Bali anyar sane katilikin salanturnyane, sane kaping sia inggih punika puisi Kena Jempulung. Ring puisi Kena Jempulung puniki kapolihang untengnyane inggih punika karma pahala. Lianan ring unteng wenten taler wirasa inguh sane karasayang ring puisi puniki lan wirama sane kaanggen inggih punika wirama sane sebet (sedih). Salanturnyane sane kaping untat taler wenten piteket sane prasida kaambil saking puisi Kena Jempulung, piteketnyane inggih punika ri kala jengah sareng anak lianan utawi kauripan puniki sapatutnyane iraga mautsaha malaksane becik, nanging sampunang malaksana corah duaning punika sane pacang ngawinang maselselan lan sengsara ungkuran.

Puisi Bali anyar sane kaping dasa inggih punika mamurda puisi Macarang Beton. Unteng saking puisi Macarang Beton puniki inggih punika pingaruh paubahan aab (pengaruh perubahan zaman). Ring puisi puniki wenten wirasa sebet sane karasayang, lianan ring punika wusan wirasa wenten taler wirama sane kaanggen ring puisi puniki inggih punika wirama sebet (sedih). Sane kaping untat piteket sane kapolihang saking puisi Macarang Beton inggih punika iraga kaaptiang prasida mineh lan milih laksana sane pacang kalaksanayang, sakadi yening wenten pingaruh lan paubahan aab, pineh-pinehin lan pilihin dumun pingaruh sane ngranjing punika, sumangdane benjang pungkur nenten masel-selan sane ngawinang lara lan sebet ring manah.

Puisi Bali anyar sane katilikin kaping solas inggih punika puisi Samaya ring Wangaya. $\mathrm{Ri}$ kala katilikin sane kapertama kapolihang indik untengnyane, inggih punika madue unteng samaya sane tan mabukti (janji busuk). Lianan ring unteng wenten taler wirasa sane karasayang inggih punika wirasa kuciwa, lan wirama sane kaanggen wenten kalih inggih punika wirama protes sareng wirama galak. Wusan unteng, wirasa lan wirama, sane kaping untat kapolihang taler piteket ring puisi Samaya ring Wangaya, piteketnyane inggih punika yening iraga dados pemimpin/sang sane makuasa ring jagate puniki sapatutnyane urati kapining krama sane ngaptiang polih wantuan, sampunang wantah ngicen samaya sane nenten mabukti kemanten, taler kaaptiang prasida dados conto sane becik majeng ring krama.

Puisi Bali anyar sane kaping roras inggih punika mamurda puisi Sungsut. Ring puisi puniki madue unteng inggih punika samaya sane tan mabukti (janji busuk). Lianan ring unteng, taler wenten wirasa sane karasayang ring tengahing puisi puniki inggih punika wirasa sungsut. Wusan wirasa wenten wirama sane kaanggen ring puisi puniki, wirama sane kaanggen inggih punika wirama sebet (sedih). Sane kaping untat wenten taler 
piteket sane kapolihang saking puisi Sungsut inggih punika iraga dados jadma sapatutnyane malaksana becik lan sane patut duaning samian punika pacang ngamolihang asil ungkuran. Yening iraga polih asil/karma sane nenten kaaptiang sampunang sebet lan masel-selan, samian punika kadadosang paplajahan sumangdane benjang pungkur nenten malaksana sakadi asapunika malih.

Puisi Bali anyar sane katilikin kaping telulas inggih punika mamurda puisi Masanding. Manut saking daging puisi Masanding puniki, kapolihang untengnyane inggih punika tresna sane matilar. Lianan ring unteng kapolihang taler wirasa sebet sane karasayang ring puisi puniki lan wirama sane kaanggen wenten kalih inggih punika wirama sebet (sedih) lan wirama galak. Sasampune unteng, wirasa lan wirama, sane kaping untat wenten piteket sane prasida kaambil saking puisi puniki. Piteketnyane inggih punika ri kala magagelan sapatutnyane iraga satya duaning punika sane ngawinang iraga nenten pacang kagoda olih anak lianan, lan yening polih masamaya tur marbarang kasujatian, sapatutnyane satya ring punika sumangdane tresna prasida kaajiang, kapangguh lan nenten malih kagoda anak lianan.

Puisi Bali anyar salanturnyane, sane katilikin kaping patbelas inggih punika puisi Raja Pisuna. Ring puisi puniki wenten unteng sane kapolihang, untengnyane inggih punika pisuna. Ri kala katilikin puisi puniki madue wirasa sungsut sane prasida karasayang lan wirama sebet (sedih) taler sane kaanggen. Ring puisi Raja Pisuna puniki taler wenten piteket sane prasida kaambil, piteketnyane inggih punika iraga dados jadma sane sampun makurenan sapatutnyane satya lan percaya kapining somah, sampunang ngraris percaya tekening reraos anak lianan, sadurung percaya takenang dumun kapatutannyane sumangdane nenten reraos punika wantah pisuna sane ngawinang iraga percaya lan ngawinang pikobet ungkuran.

Puisi Bali anyar sane kaping limolas inggih punika mamurda puisi Ngidam Bulan. Unteng sane kapolihang saking puisi puniki inggih punika tresna nenten sida gelahang. Ring puisi puniki taler wenten wirasa sebet sane karasayang lan wenten wirama sebet (sedih) sane kaanggen. Lianan ring unteng, wirasa lan wirama ring puisi sane mamurda Ngidam Bulan puniki taler wenten piteket sane kapolihang. Piteket sane prasida kaambil saking puisi puniki inggih punika ri kala tresna kapining anak lianan, sampunang iraga belog sane ngawinang buta lan mangantosang tresna sane nenten pastika pacang kagelahang lan cingakin dumun napike sang sane kaantosang punika pacang tresna mawali kapining iraga.

Puisi Bali anyar sane katilikin salanturnyane, sane kaping enembelas inggih punika puisi Kuluk Bengil. Unteng sane kapolihang ring puisi puniki inggih punika parilaksana corah. Lianan ring unteng wenten taler wirasa gedeg sane karasayang lan wirama galak sane kaanggen ring puisi puniki. Wusan ngamolihang unteng, wirasa lan wirama, sane kaping untat kapolihang taler piteket ring puisi puniki. Piteketnyane inggih punika ring sajeroning krama sapatutnyane iraga prasida manyama braya sane becik, iraga patut milih lan mineh-minehin laksana sana patut kalaksanayang, sumangdane nenten punika sane ngawinang iraga nenten kasenengin ring sajeroning krama, lianan ring punika taler yening malaksana corah ungkuran prasida polih karma sane ngawinang sengsara lan sesel.

Puisi Bali anyar sane kaping pitulas inggih punika mamurda puisi Buta Nyumu Kedat. Manut saking daging puisi Buta Nyumu Kedat puniki kapolihang untengnyane, inggih punika karma pahala. Ring sajroning puisi puniki taler wenten wirasa bagia sane karasayang lan wirama ngundukang (persuasif) sane kaanggen. Yening sampun polih unteng, wirasa lan wiramanyane, sane kaping untat wenten piteket sane prasida kaambil saking puisi Buta Nyumu Kedat puniki. Piteketnyane inggih punika sapatutnyane iraga malaksanan sane becik lan patut, sumangdane benjaang pungkur prasida ngamolihang pajalan utawi pahala sane becik taler. Lianan ring punika iraga taler 
kaaptiang prasida mineh lan milihin laksana sane pacang kalaksanayang sumangdane ungkuran iraga nenten masel-selan.

Puisi Bali anyar sane kaping plekutus inggih punika puisi Tiwas. Manut saking daging puisi Tiwas punika kapolihang untengnyane inggih punika pajatuh karma (takdir). Ring sajeroning puisi puniki wenten taler wirasa sebet sane karasayang lan wirama sane kaanggen inggih punika wirama sebet (sedih). Sasampune kapolihin unteng, wirasa lan wiramanyane, sane kaping untat kapolihang taler piteket saking puisi Tiwas puniki. Piteket sane prasida kaambil inggih punika yening iraga tiwas sampunang masel-selan tekening kauripane mangkin, satata maturan, malajah lan mautsaha patut kalaksanayang sumangdane polih pakaryanan sane becik lan polih rejeki sane akeh, sane prasida ngawinang bejang pungkur nenten tiwas malih.

Puisi Bali anyar salanturnyane, sane kaping siangolas inggih punika mamurda puisi Bajang Malong. Ring sajeroning puisi puniki wenten madue unteng inggih punika kukuh (tetap pendirian). Lianan ring unteng wenten taler wirasa pageh (kukuh) sane karasayang lan wirama sane kaanggen ring puisi puniki inggih punika wirama kukuh. Sawusan unteng, wirasa, lan wirama, sane kaping untat wenten taler piteket sane kapolihang ring puisi Bajang Malong puniki. Piteket sane prasida kaambil inggih punika yening iraga dados anak istri sapatutnyane malaksana sane becik, ngawinang arum kulawarga, madue kaluihan lan nenten aluh kagoda anak lanang. Lianan ring punika yening iraga meled pacang ngukuhang bajang punika nenten wenten iwangnyane, nanging sampunang nurus ngukuhang bajang nyantos dados bajang malong (bajang tua).

Puisi Bali anyar sane katilikin kaping untat, kaping duang dasa inggih punika mamurda puisi Ciri-ciri. Puisi Ciriciri puniki madue unteng inggih punika ciren anak luh Bali. Lianan ring unteng wenten taler wirasa sane karasayang inggih punika wirasa kuciwa, lianan ring punika wenten taler kalih wirama sane karasayang ring puisi puniki sakadi wirama nyantenang (sugestif) lan wirama sebet (sedih). Sasampune kapolihin unteng, wirasa lan wiramanyane, sane kaping untat kapolihang piteketnyane inggih punika yening dados anak luh Bali sampunang lali tekening tetamian Bali, iraga sapatutnyane prasida taler ngalestariang tetamian Baline punika, duaning samian punika dados ceciren/cihna anak luh Bali sane luih. Lianan ring punika taler sampunang iraga ngulah aluh keni iusan sane ngranjing, pilih lan pineh-pinehin dumun sumangdane iraga nenten pacang lali tekening budaya sane wenten.

Punika taler basita paribasa sane wenten ring pupulan puisi Bali anyar Sang Kinasih wenten 7 soroh sane akehnyane 22 imba, inggih punika minakadi (1) sesonggan kapolihang 9 imba, (2) sesenggakan kapolihang 3 imba, (3) bebladbadan kapolihang 1 imba, (4) sesawangan kapolihang 6 imba, (5) papindan kapolihang 1 imba, (6) cecangkitan kapolihang 1 imba, lan (7) sesimbing kapolihang 1 imba. Samian pikolih lan tetepasan sane mapaiketan sareng basita paribasa pacang katelatarang ring sor.

Basita paribasa soroh sesonggan ring pupulan puisi Bali anyar Sang Kinasih kakeniang 9 imba. Saking 9 imba punika kapolihang saking 8 murda puisi, inggih punika Kacangkik, Kembang Bintang, Macarang Beton, Raja Pisuna, Ngidam Bulan, Kuluk Bengil, Tiwas, lan Bajang Malong

Basita paribasa soroh sesenggakan ring pupulan puisi Bali anyar Sang Kinasih kakeniang 3 imba. Saking 3 imba punika kapolihang saking 3 murda puisi, inggih punika Kena Jempulung, Tan Eling, lan semaya ring wangaya.

Basita paribasa salanturnyane soroh bebladbadan kakeniang wantah asiki ring pupulan puisi Bali anyar Sang Kinasih, imba bebladbadan punika wenten ring murda puisi Madamar di Langit.

Basita paribasa soroh sesawangan ring pupulan puisi Bali anyar Sang Kinasih kakeniang 6 imba. Saking 6 imba punika kapolihang saking 6 murda puisi, inggih 
punika Indria Tan Pawates, Dadi Caru, Sungsut, Buta Nyumu Kedat, Masanding, lan Ciri-ciri.

Basita paribasa soroh papindan kakeniang wantah asiki ring pupulan puisi Bali anyar Sang Kinasih, imba papindan punika wenten ring murda puisi Ngidam Bulan.

Basita paribasa salanturnyane soroh cecangkitan kakeniang wantah asiki ring pupulan puisi Bali anyar Sang Kinasih, imba cecangkitan punika wenten ring murda puisi Gumi Blabar.

Basita paribasa sane kaping untat kapolihang ring pupulan puisi Bali anyar Sang Kinasih inggih punika sasimbing. Imba sasimbing kakeniang wantah asiki saking asiki murda puisi inggih punika puisi Muncuk Bagia.

Tetilik wangun jroning karya sastra lan mustika paajah-ajahan pawatekan sajeroning karya sastra sujatinnyane sampun kalaksanayang olih panilik lianan. Mawit saking kawentenane punika panilik nyaihang pikolih lan tetepasan tetilik puniki sareng tetilik panilik lianan, sakadi: (1) "Seseleh Tata Wangun Jeroning Puisi (Unsur Intrinsik) lan Kajatian Guna Sarat Paguron-guron (Nilai Pendidikan Karakter) Sajeroning Puisi Bali Anyar ring Pangkaja Sari Kelas IX" olih Ni Putu Mirah Yunisa Putri warsa 2015. Nilikin indik tata wangun jeroning puisi, dadosnyane pateh sareng tetilik puniki. Puisi Bali anyar ring Pangkaja Sari katilik wantah 5 murda, nanging ring tetilik puniki duang dasa murda puisi. (2) "Seseleh Basita Paribasa miwah Guna Sarat Paajah-ajahan Karakter Sajeroning Dolanan ring Gong Kebyar Alit-alit Duta Kabupaten Gianyar Warsa 2014" olih I Putu Adi Darmadi warsa 2015. Kapolihang limolas basita paribasa, dadosnyane pateh sareng tetilik puniki. Basita paribasa kapolihang 5 soroh, yening tetilik puniki kapolihang 7 soroh basita paribasa.

Manut kawentenan ring ajeng, sesampune kasaihang pantaraning tetilik puniki sareng tetilik Ni Putu Mirah Yunisa Putri lan I Putu Adi Darmadi prasida kawedarang pabinayannyane sakadi, sane kapertama pabinayan sareng tetilik Ni Putu Mirah Yunisa Putri (2015) inggih punika tetilik puniki akehan nilikin puisi
Bali anyar inggih punika 20 murda puisi Bali anyar, nanging ring tetilik $\mathrm{Ni}$ Putu Mirah Yunisa Putri wantah nilikin 5 murda puisi kemanten. Kaping kalih pabinayan sareng tetilik I Putu Adi Darmadi (2015) inggih punika tetilik puniki akehan ngamolihang basita paribasa inggih punika ngamolihang 22 imba basita paribasa saking 7 soroh basita paribasa, nanging ring tetilik I Putu Adi Darmadi wantah ngamolihang 8 imba basita paribasa saking 5 soroh basita paribasa. Lianan ring punika, tetilik puniki taler akehan ngamolihang imba basita paribasa sane anyar, sane durung kaunggahang ring buku Simpen, nanging ring tetilik I Putu Adi Darmadi akehan imba basita paribasanyane sampun wenten katelatarang ring buku.

\section{PAMUPUT}

Manut pikolih lan tetepasan tetilik sane sampun katelatarang lan sampun kapolihang saking nganggen kramaning dokumentasi, prasida kacutetang yening struktur batin (tata wangun manah) ring pupulan puisi Bali anyar Sang Kinasih pakardin Ni Kadek Widiasih wenten patpat inggih punika (1) unteng (tema), (2) wirasa (rasa/feeling), (3) wirama (nada), (4) piteket (amanat). Wenten duang dasa murda puisi Bali anyar sane katilikin inggih punika puisi sane mamurda Indria Tan Pawates, Gumi Blabar, Kacangkik, Dadi Caru, Muncuk Bagia, Tan Eling, Kembang Bintang, Madamar di Langit, Kena Jempulung, Macarang Beton, Semaya ring Wangaya, Sungsut, Masanding, Raja Pisuna, Ngidam Bulan, Kuluk Bengil, Buta Nyumu Kedat, Tiwas, Bajang Malong, Ian Ciri-ciri.

Basita paribasa sane wenten ring pupulan puisi Bali anyar Sang Kinasih punika wenten 7 soroh basita paribasa saking 15 soroh basita paribasa sane kaanggen ring sepat siku-siku. Taler indik akehnyane kakeniang antuk 22 imba, basita paribasa punika sakadi, Sesonggan wenten 9 imba, Sesenggakan wenten 3 imba, Bebladbadan (Methapora) wenten siki imba, Sesawangan (Perumpamaan) wenten 6 imba, Papindan wenten siki imba, Cecangkitan (olok- 
olokan) wenten siki imba, lan Sesimbing (Sindiran) taler wenten siki imba. Dadosnyane, basita paribasa soroh sesonggan sane pinih akeh kapikolihang ring pupulan puisi Bali anyar Sang Kinasih. Basita paribasa sane nenten kapolihang inggih punika wewangsalan, peparikan, sloka, cecimpedan, cecangkriman, raos ngempelin, sasemon lan sipta.

Piteket ring sajeroning tetilik puniki inggih punika: (1) mangda prasida kaanggen dasar ring sajeroning pangresep indik struktur batin (tata wangun manah) ring sajeroning puisi utamannyane ring puisi Bali anyar, (2) mangda prasida dados dasar ri tatkala pacang nincapang kawagedan indik basita paribasa sane kasurat ring kria sastra utamannyane ring puisi Bali anyar, (3) majeng ring panilik lianan mangda sida nglimbakang malih indik daging tetilikan sane mapaiketan sareng struktur batin (tata wangun manah) lan basita paribasa ring kria sastra puisi Bali anyar.

\section{KAPUSTAKAAN}

Aminuddin. 2004. Pengantar Apersepsi Karya Sastra. Bandung: Sinar Baru Algensino.

Antara, I Gusti Putu.2011. Frosa Fiksi Bali. Singaraja. Yayasan Gita Wandawa.

Darmadi, I Putu Adi. 2015. Seseleh Basita Paribasa miwah Guna Sarat Paajahajahan Karakter Sajeroning Dolanan ring Gong Kebyar Alit-alit Duta Kabupaten Gianyar Warsa 2014. Skripsi (nenten kamijilang). Jurusan pendidikan Bahasa Bali, FBS, Undiksha Singaraja.

Gautama, Wayan Budha. 2007. Kesusastraan Bali. Cakepan Penuntun Mlajahin Kesusastraan Bali. Gianyar: Paramitha.

Putri, Ni Putu Mirah Yunisa. 2015. Seseleh Tata Wangun Jeroning Puisi (Unsur Intrinsik) lan Kajatian Guna Sarat Paguron-guron (Nilai Pendidikan Karakter) Sajeroning Puisi Bali Anyar ring Pangkaja Sari Kelas IX".Skripsi (tidak diterbitkan). Jurusan pendidikan Bahasa Bali, FBS, Undiksha Singaraja.

Redana, Made. 2004. Panduan Praktis Penulisan Karya IImiah dan Proposal Riset. Denpasar: IHDN.

Saputra, N Kanduk. 2010. Kamus Bahasa Bali. Denpasar: CV. Kayumas Agung.

Simpen, Wayan. 1988. Basita Paribasa. Gunasta: Muspa grafika.

Tinggen, I Nengah. 2005. Cecimpedan lan Beladbadan. Bubunan: Indra Jaya.

Utami, N.S. 2013. 4 PM Pintar Berpantun, Puisi, Pribahasa dan Majas. Yogyakarta: Naafi Book Media.

Waluyo, Hermawan J. 1987. Teori dan Apersepsi Puisi. Jakarta: Erlangga.

Widiasih, Ni Kadek. 2015. Sang Kinasih (Pupulan Puisi Bali Anyar). Singaraja: Buku Arti. 